\title{
The Mediator Effect of Reading Comprehension in the Relationship between Logical Reasoning and Word Problem Solving
}

\author{
Derya Can* \\ Burdur Mehmet Akif Ersoy University, Faculty of Education, Burdur, Turkey \\ ORCID: 0000-0003-1257-8793
}

Article history

Received:

15.04.2020

Received in revised form: 11.06.2020

Accepted:

24.06.2020

Key words:

Logical reasoning; reading comprehension; word problem solving; mediating role
Reading comprehension skill is seen as a predictor of word problemsolving performance, and the close relationship between reading comprehension and mathematical skills is accentuated. On the other hand, more research is needed as to determine how logical thinking and word problem solving are related to each other and to analyze the role of reading comprehension in this relationship. The aim of the study is to examine the role of reading comprehension in the relation between logical reasoning and word problem-solving in 158 fourth grade primary school students. The data were collected through the administration of logical reasoning, syllogistic reasoning, and reading comprehension tests, and word problems. In this research, which makes use of a predictive correlational research model, the regression analysis was used to test the direct and indirect relationships between word problem solving, logical reasoning, inference making, and reading comprehension skills. As a result of the research, the relationships between the variables were found to be positively significant. Besides, reading comprehension seems to play a partial mediating role in the relationship between logical reasoning and word problem-solving. The positive correlation between word problem solving and logical reasoning skills suggests that activities to improve word problem-solving performance should be supported by logical reasoning- and inference making-related activities. The fact that reading comprehension skills play a mediating role between these two performances reveals the importance of linguistic skills such as reading comprehension in the development of logical and mathematical thinking.

\section{Introduction}

Word problem-solving skills play an important role in mathematics education (Timmermans, Van Lieshout, \& Verhoeven, 2007). Word problems contain word descriptions about problem situations in which answers to one or more mathematical questions are searched using numerical data and operations (Verschaffel, Greer, \& De Corte, 2000). The Primary School Mathematics Curriculum developed by the Ministry of National Education (MoNE) puts a special emphasis on the acquisition of word problem solving ability which requires the use of four operations (MoNE, 2018). For instance, in a problem statement like "Ayşe has nine pencils. She gave three of them to her friend. So how many pencils does Ayşe

\footnotetext{
* Correspondency: deryacakmak@ mehmetakif.edu.tr
} 
have now?" students should be familiar with the linguistic and numerical knowledge given in the problem and solve the problems based on their recognition of the required operations. This suggests that word problem-solving skills require different cognitive skills such as reasoning and reading comprehension in addition to mathematical skills (Andersson, 2007; Fuchs, Fuchs, Compton, Powell, Seethaler, Capizzi \& Fletcher, 2006; Fuchs, Fuchs, Stuebing, Fletcher, Hamlett, \& Lambert, 2008; Jordan, Levine, \& Huttenlocher, 1995).

Although arithmetic operations are one of the requirements to solve word problems, some cognitive skills related to word problem-solving process require different abilities other than arithmetical skills or calculation (Fuchs et. al., 2006). For instance, it would be much easier for students to solve a problem given in the form of $9-3=$ ? which is numerical rather than to solve a word problem. Word problems may increase the likelihood that some students will have difficulty in solving the problems even though they have sufficient mathematical skills (Swanson, Jerman, \& Zheng, 2008). Word problems are generally related to real-world instances and require students to comprehend the mathematical knowledge in the problem (Bae, Chiang, \& Hickson, 2015), to employ necessary strategies and calculation skills (De Corte \& Verschaffel, 1987) and logical inferences (Tajika, Nakatsu, Nozaki, Neumann, \& Maruno, 2007). Some studies deal with the relationships between logical reasoning skills and mathematical reasoning skills (Attridge \& Inglis, 2013; Inglis \& Simpson, 2009; Morsanyi, McCormack, \& O'Mahony, 2018; Morsanyi \& Szücs, 2015). A limited number of studies have handled the correlations between logical reasoning and a specific mathematical skill or a mathematical topic (Attridge \& Inglis, 2013; Morsanyi, McCormack \& O'Mahony, 2018; Nunes, Bryant, Evans, Bell, Gardner, Gardner \& Carraher, 2007). For this reason, it is thought that more research is needed on how logical reasoning and inference making skills are related to word problem-solving skills.

Students who are good at solving word problems can successfully use their conceptual understanding, and word knowledge of problems to reach the correct results (Devidal, Barrouillet \& Fayol, 2007). This is an indication that word problem solving also requires a cognitive process that includes reading comprehension (Fuchs, Fuchs, Compton, Hamlett \& Wang, 2015; Kintsch \& Greeno, 1985). Research suggests that there is a strong relationship between reading comprehension and word problem solving or mathematics performance (Pape, 2004; Vilenius-Tuohimaa, Aunola \& Nurmi, 2008). When the cognitive skills used by primary school students in solving word and operational problems are examined, it is observed that students with low reading comprehension skills can solve operational problems, but have difficulty in solving word problems (Pimperton \& Nation, 2010). The findings suggest that reading comprehension has a significant role in mathematical performance (Pape, 2004; Vilenius-Tuohimaa, Aunola \& Nurmi, 2008). However, although there are also studies indicating that there is a positive and significant relationship between reading skills and mathematics performance, it is also reported that this relationship is not statistically significant ( $\mathrm{r}=0.162, \mathrm{p}>$.05) (Imam, Abas-Mastura \& Jamil, 2013; Imam, 2016). Due to such inconclusive findings, more studies examining the relationship between reading comprehension and word problem-solving performance will contribute to the literature.

Some studies concentrate upon the relationship between logical thinking and mathematical performance (Attridge \& Inglis, 2013; Inglis \&Simpson, 2009; Morsanyi, McCormack \& O'Mahony, 2018; Morsanyi \& Szücs, 2015), on the relationship between reading comprehension and the performance of solving word problems (Pape, 2004; VileniusTuohimaa, Aunola, \& Nurmi, 2008), on the relationship between inference making which is a significant component of logical thinking and reading comprehension (Cain \& Oakhill, 1999; 
Segers \& Verhoeven, 2016). That being said, what is aimed to be answered within the scope of this research is the role of students' reading comprehension skills in the relationship between their logical reasoning skills and their word problem-solving performances. It is predicted that students with advanced logical reasoning skills may have higher levels of mathematical performance and word problem-solving performance. Nevertheless, it is a matter of curiosity on how logical reasoning affects the students' word problem solving performance whose reading comprehension skills are not sufficiently developed. Therefore, in this study, the relationship between word problem-solving skills and logical thinking skill are examined, and it is aimed to determine whether reading comprehension has a significant mediating role in this regard.

\section{Theoretical framework Logical Reasoning and Word Problem-Solving}

Logical reasoning requires the ability to draw conclusions based on the premises given. When a researcher is working on logical reasoning skills, they should explain the participants that they should not consider the true meaning of premises and results, and that premises should be considered true even if they are not true in real life (Morsanyi \& Handley, 2012). This is significant since logical reasoning problems can be designed to include logical contrasts with participants' beliefs or intuition.

Mathematical thinking and logical thinking require the use of some normative rules to draw conclusions, to abstract and produce symbolic content based on the premises given (Morsanyi \& Szücs, 2015). For instance, in regard to the basic arithmetical operations, it is possible to describe addition as the combination of numbers and multiplication as the repeated addition of the same numbers. It is easy to realize these operations involving small numbers (for instance, $5+1,2 \times 3)$ mentally, it becomes harder to make mental operations with larger numbers or fractions. This strongly suggests that complex cognitive processes function even at the most basic level of mathematical thinking. One of these cognitive requirements is symbolic or abstract representations. Mathematical reasoning requires the use of certain rules, achieving results based on the information given, and the integration of the information into the process. This process directly coincides with the reasoning skills routinely used in the logical thinking process. Based on this similarity it is expected that mathematical skills have a strong relation with logical thinking skills (Morsanyi \& Szücs, 2015). For instance, Handley, Capon, Beveridge, Dennis, and Evans (2004) found that there is a high level of correlation between children's logical thinking skill and their performance in a standardized mathematics test $(\mathrm{r}(30)=0.63 \mathrm{p}<.001)$. Inglis and Simpson (2009) analyzed the relationship between mathematical reasoning skills and conditional reasoning. They conclude that mathematics undergraduate students perform better than intelligence-matched art students. Attridge and Inglis (2013) examined the changes in the conditional reasoning skills of undergraduate mathematics and English literature students. It is found that the conditional reasoning skills of the latter group did not change for one year, but those of the former group improved in the same period. Morsanyi, McCormack, and O'Mahony (2018) found a correlation between deductive inference and mathematical reasoning skills through a sample of adults. In the study by Nunes et. al. (2007), it was concluded that the logical competencies of primary school students made an important contribution to predict their school achievements. Although there are limited previous findings on the comprehension of logical relations in mathematical learning (Attridge \& Inglis, 2013; Morsanyi, McCormack \& O’Mahony, 2018; Nunes et.al., 2007), it is commonly stated that mathematics education improves students' general reasoning skills. It is explained by the fact that mathematical and logical reasoning requires a similar 
inferential process. This is because logic is reported to be the prerequisite of mathematical knowledge (Piaget, 1952; Russell, 1919). Based on these findings, logical thinking skill is predicted to be related to word problem solving performance. According to the data obtained from the determined sample group, the following hypothesis is developed to examine this relationship:

\section{H1: Logical reasoning skills positively affect word problem solving performance. Logical Reasoning and Reading Comprehension}

Reading comprehension involves the lower and higher-level linguistic skills (Cain, Oakhill \& Bryant, 2004) and requires the ability to make inferences to have a full understanding of a text (Oakhill \& Cain, 2012). Making inferences requires the reader to follow certain logical steps to draw conclusions depending on the premises given in the text. It enables individuals to comprehend those points which are not overtly included in the texts. Whilst the ability to make inferences partially predicts reading comprehension, individuals with low reading comprehension skills are found to have insufficient ability to infer (Cain \& Oakhill, 1999). Based on the assumption that logical thinking and inference making skills may be related to reading comprehension, the following hypothesis is developed in the study:

\section{H2: Logical reasoning positively affects reading comprehension. Logical Reasoning, Reading Comprehension and Word Problem Solving}

Word problem-solving skill is seen as an important strategic tool in the development of basic level literacy and numeracy skills. Research clearly indicates that there is a strong relationship between literacy skills and mathematical skills and that those students whose literacy skills are good also have better mathematical performance (Koponen, Aunola, Ahonen, \& Nurmi, 2007). Studies on this subject mostly focus on the relationship between reading fluency and math skills yet the previous findings on revealing the role of reading comprehension in mathematics performance are more limited (Björna, Aunolab \& Nurmi, 2016; DeCorte \& Verschaffel, 1987). For instance, in a study with a sample of fourth-grade students, it is found that students' reading skills are closely related to their word problemsolving skills (Vilenius-Tuohimaa, Aunola, \& Nurmi, 2008). In this study, it is emphasized that reading skill should be improved in order to better understand the word problems in mathematics. If it is well-developed, then the students can better make use of contextual information which supports the problem-solving process. Thus, students will be able to better plan how to proceed in the mathematical part of the problem. In other words, versatile reading skills contribute to good performance in solving word problems (De Smedt, Taylor, Archibald, \& Ansari, 2010). There are some findings which suggest a direct relationship between reading comprehension and solving the word problems (Pape, 2004; VileniusTuohimaa, Aunola, \& Nurmi, 2008). Nonetheless, some studies reveal that such a relationship is not statistically significant $(r=0.162, p>.05$; Imam, Abas-Mastura \& Jamil, 2013; Imam, 2016). Reading comprehension also calls for high-level cognitive skills so as to be able to support understanding the text (Yuill \& Oakhill, 1991). The findings pinpoint that the inference skill is closely related to the development of the skills concerning reading comprehension (Imam, 2016; Yuill \& Oakhill, 1991).

Reading comprehension skill is seen as a predictor of word problem-solving performance, and the close relationship between reading comprehension and mathematical skills is accentuated (Vilenius-Tuohimaa, Aunola, \& Nurmi, 2008). On the other hand, more research is needed as to determine how logical thinking and word problem solving are related to each other and to 
analyze the role of reading comprehension in this relationship. The fact that students with a higher level of logical thinking skills have higher word problem-solving performance is an expected situation considering the relationship between logic and mathematics. Notwithstanding, if the student's logical thinking skills and their reading comprehension skills are not sufficiently developed, how effective can these skills be on their word problemsolving performance? In order to answer this question, students' word problem solving performance is analyzed based on their logical reasoning and reading comprehension skills. In this context, the relationship between students' word problem solving and logical reasoning will be studied, and the role of reading comprehension in this relationship will be investigated. The hypothesis put forward in this regard is as follows:

H3: Reading comprehension mediates the relationship between logical reasoning and word problem solving.

The conceptual model developed on the basis of the hypotheses given above is presented in Figure 1. In the model, logical reasoning and syllogistic reasoning are the independent variables and word problem solving is the dependent variable and reading comprehension ability plays a mediator role in this relationship.

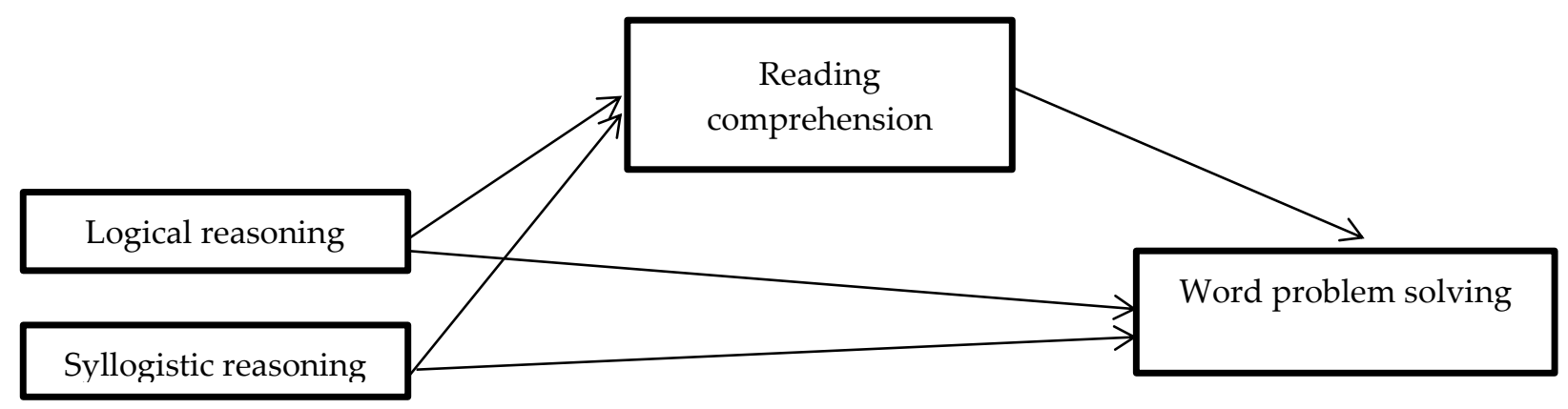

Figure 1. The conceptual model for the relationship between the variables in the study

\section{Method}

In this research, a predictive correlational research model was used, which allows examining the relationship between variables without any intervention to affect the relationship between two or more variables. Predictive correlational studies make it possible to explain the change in the dependent variable depending on one or more independent variables (Fraenkel, Wallen \& Hyun, 2012).

\section{Sample}

Sample selection was realized by convenience sampling. 158 fourth grade primary school students participated in the study. Of them 75 (47,5\%) are female and 83(52,5\%) male. Their age ranges between 9 and 10. After four years of primary school education in Turkey, students attend middle schools. When the educational programs of the primary school Mathematics and Turkish courses (MONE, 2018) are considered, it is witnessed that students are expected to acquire the targeted skills such as logical thinking, inference making, reading comprehension, and problem-solving skills after four years of primary education. The gap between the students who graduate with and without acquiring these skills may get even bigger in the following years (Spencer, Fuchs \& Fuchs, 2020). For this reason, 4th-grade primary school students were included in the study, and the role of their logical thinking and reading comprehension skills in word problem-solving performances is dwelled upon. 


\section{Data collection tools \\ Logical Reasoning Test}

The test of logical reasoning ability was developed by Can, Altunya, and Can (2019) to measure the logical thinking skills of children aged 8-12. The test has four dimensions: Reasoning methods, principles of reasoning, classification, and concept-definition. It includes a total of 18 items. The original KR-20 internal consistency coefficient of the test is found to be 0,81 . In the present study, it is detected as 0,83 . According to the confirmatory factor analysis conducted on the data, the four-factor model was found to have an acceptable goodness of fit, $\mathrm{X}^{2}=221,22(\mathrm{sd}=129) \mathrm{X}^{2} / \mathrm{sd}=1,71 \mathrm{RMSEA}=0,045 ; \mathrm{RMR}=0,013$; GFI=0,93; $\mathrm{AGFI}=0,91 ; \mathrm{CFI}=0,90$.

\section{Syllogistic Reasoning Test}

Syllogistic reasoning test was developed by Schröeder, Boedeker, and Edelstein (2000). The test has two subtests each with ten items. In one of these subtests, there are items which are about basic level logical syllogisms termed as "modus ponens" and "modus tollens". The items in the other subtest are about indeterminate inferences which require more complex reasoning skills. The items of logical syllogisms require the answers of yes or no. The items of indeterminate inference require the use of an answer of "maybe". In the test, the participants are given a context and are asked to answer the related items choosing one of the answers: "yes", "no", and "maybe". The children were instructed in a way that warrants that they just had to mark an answer which they thought the correct answer. An example item is given as follows: "All seals that eat delicious fish are happy." (A) Seal 1 has eaten delicious fish. Is Seal 1 happy? (Answer: yes). (B) Seal 2 did not eat any delicious fish. Is Seal 2 happy? (Answer: maybe). The Cronbach's Alpha reliability coefficient of the test is found to be 0,78 .

\section{Reading Comprehension Test}

The reading comprehension test was developed by Çetinkaya Özdemir and Akyol (2019). It is used to evaluate children's reading comprehension. The original KR-20 reliability coefficient of the test was found to be 0.83 . In the present study, it is found to be 0,82 . The test consists of 22 items. The maximum score that can be obtained from the test is 22 , and the minimum score is zero. There are two types of the text found in the test: narrative and informative. The length of each text varies from half a page to a page. During the implementation process, the participants were asked to read the texts and then, answer multiple-choice questions. There are eleven items per text.

\section{Word Problem Test}

To determine the performance of the students with regard to the word problems, context-based problems were developed by Can and Yetkin Özdemir (2019) are employed to delve into students' problem-solving performance. These questions are categorized under three different components: using a reference point, flexible calculation, and using number size. Students who reach mathematically correct results are given 1 point, and the ones who provide incorrect answers or no answers are given 0 points. The KR-20 internal consistency coefficient of the test is found to be 0,87 in the study. In addition to that, as a result of confirmatory factor analysis, it is observed that the three-factor model had an acceptable goodness of fit, $\mathrm{X}^{2}=47,74(\mathrm{sd}=32) \mathrm{X}^{2} / \mathrm{sd}=1,49 \mathrm{RMSEA}=0,032 ; \mathrm{SRMR}=0,032 ; \mathrm{CFI}=0,99$. 


\section{Data collection procedure}

Before the data of the study were collected, necessary permissions were obtained from the Burdur Provincial Directorate of National Education following the principles of research ethics. Next, the school administration, teachers, and students were informed about the purpose of the study. During the process of data collection tools, the tests were applied by the researcher together with the teachers. It was stated that personal information would remain confidential during the study and the volunteering principle of the participants was taken into consideration. Besides, the students were informed about the fact that the scores they would get from the measurement tools would not affect their school achievement. The data collection was carried out in the spring semester of the 2018-2019 academic year and lasted about two class hours.

\section{Data analysis}

The mediation model is a statistical technique where the maximum effect of the independent variable on the dependent variable can be checked as well as analyzing the productivity effect of the mediator variables (Baron \& Kenny, 1986; Iacobucci, 2008). With a view to testing the model several statistical techniques are used: path analysis, structural equation modeling, and regression analysis (Burmaoğlu, Polat \& Meydan, 2013; cited in Koğar, 2015). It is determined that multiple regression analysis shows the best performance even if the independent variable is measured categorically (Cohen, Cohen, West \& Aiken, 2003; cited in Koğar, 2015). In this study, the direct and indirect effects of logical reasoning which is the independent variable and reading comprehension as a mediator variable on problem-solving performance were investigated by multiple regression analysis. Assumptions of multiple regression analysis were tested. By analyzing $\mathrm{z}$ values, outliers, and marginal values calculated based on their Mahalanobis distance are removed from the dataset.

Baron and Kenny (1986) defined the mediator variable as a variable that explains the relationship between the predictor and the dependent variable. In the model proposed in the present study, it is accepted that reading comprehension skill acts as a mediator between logical reasoning and word problem solving performance of the participants (Figure 1). To test the mediator model, firstly, the conditions that the relationships between the variables must meet were analyzed and mediator analysis was performed using the Process add-on in SPSS (Hayes, 2013). Hayes (2013) argues that the resampling technique called "bootstrapping" analysis, which creates the sampling distribution of indirect effects, is the most powerful and valid mediator test. Also, given that the confidence interval for the indirect effect does not contain zero it reveals a statistically significant mediating effect (Hayes, 2013).

The mediator model suggests that the data collected from the logical reasoning and syllogistic reasoning tests are the independent variables, those from the reading comprehension test are the mediator variable, and those from the word problem-solving test are the dependent variables. This model requires that four conditions should be met to develop mediator relations (Baron \& Kenny, 1986). These conditions required are as follows: (a) the effects of the independent variables on the dependent variables should be significant, (b) the effects of the independent variables on the mediator variable should be significant, (c) when the effects of the independent variables are controlled, the mediator variable should significantly predict the dependent variable, and (d) when the effects of the mediator variable are controlled, the correlations between the independent and dependent variables should reduce or these 
correlations should not be significant. These relationships between variables were analyzed by the multiple regression analysis, and whether conditions were met or not were checked.

\section{Results}

Descriptive statistics are used to summarize the performance of primary school fourthgrade students with respect to the word problem solving, logical reasoning, inference making, and reading comprehension skills. The average scores, possible ranges, observed ranges, standard deviation, skewness, and kurtosis coefficients regarding the data obtained from each measurement tool are given in Table 1 bearing in mind the sub-dimensions in the tests.

Table 1. Descriptive statistics $(n=158)$

\begin{tabular}{|c|c|c|c|c|c|c|c|}
\hline Variables & Items & $\begin{array}{l}\text { Possible } \\
\text { range }\end{array}$ & $\begin{array}{l}\text { Observed } \\
\text { range }\end{array}$ & M & ss & Skewness & Kurtosis \\
\hline Reading comprehension & 22 & $0-22$ & $2-22$ & 16,89 & 4,02 & $-1,302$ & 1,867 \\
\hline $\begin{array}{l}\text { Mathematical word } \\
\text { problems }\end{array}$ & 10 & $0-10$ & $0-10$ & 7,34 & 2,14 & $-0,962$ & 0,476 \\
\hline \multicolumn{8}{|l|}{ Sub-dimensions } \\
\hline Using a reference point & 3 & $0-3$ & $0-3$ & 2,32 & 0,84 & $-1,041$ & 0,240 \\
\hline Flexibility in calculation & 4 & $0-4$ & $0-4$ & 2,92 & 1,09 & $-0,711$ & $-0,458$ \\
\hline $\begin{array}{l}\text { Understanding of the } \\
\text { number size }\end{array}$ & 3 & $0-3$ & $0-3$ & 2,09 & 0,84 & $-0,570$ & $-0,450$ \\
\hline Logical Reasoning & 18 & $0-18$ & $3-16$ & 10,82 & 3,20 & $-0,270$ & $-0,838$ \\
\hline \multicolumn{8}{|l|}{ Sub-dimensions } \\
\hline Reasoning & 7 & $0-7$ & $0-7$ & 3,80 & 1,70 & $-0,222$ & $-0,708$ \\
\hline Reasoning principles & 3 & $0-3$ & $0-3$ & 2,45 & 0,736 & $-1,230$ & 1,000 \\
\hline Classification & 4 & $0-4$ & $0-4$ & 2,61 & 1,13 & $-0,473$ & $-0,660$ \\
\hline Concept-definition & 4 & $0-4$ & $0-4$ & 1,95 & 1,18 & 0,005 & $-0,701$ \\
\hline Syllogistic reasoning & 20 & $0-20$ & $4-17$ & 9,69 & 2,34 & 0,110 & 0,683 \\
\hline \multicolumn{8}{|l|}{ Sub-dimensions } \\
\hline Logical syllogisms & 10 & $0-10$ & $1-10$ & 7,47 & 2,10 & $-0,882$ & 0,417 \\
\hline Indeterminate syllogisms & 10 & $0-10$ & $0-8$ & 2,22 & 2,02 & 0,810 & 0,005 \\
\hline
\end{tabular}

Table 1 shows that skewness and kurtosis values are within the acceptable ranges based on the assumptions of Kline (2011). The word problem-solving performance of the students did not show a significant change between the sub-dimensions. It is found that the students were able to use their logical thinking skills most effectively in the reasoning dimension and the least in the concept-definition dimension. The data from the syllogistic reasoning test show that in the logical syllogisms subdimension the correct answer by the participants is $74,4 \%$ whereas it is $22,2 \%$ for the indeterminate syllogisms. The performance difference observed in the two subdimensions of the test is statistically significant, $\mathrm{t}_{(157)}=5.25 \mathrm{p}<.01, \mathrm{~d}=3.40$. In the logical syllogisms subtest $35 \%$ of the participants get a score of 9 and $27 \%$ of them get a score of 10 . However, in the indeterminate syllogisms' subtest no participant gets the scores of 9 or 10 , and $13 \%$ of the participants get 6 or lower scores. 
Table 2. Relationships between variables and their sub-dimensions

\begin{tabular}{|c|c|c|c|c|c|c|c|c|}
\hline \multirow{2}{*}{\multicolumn{2}{|c|}{ Variables }} & \multicolumn{4}{|c|}{ Logical reasoning } & \multicolumn{3}{|c|}{ Syllogistic reasoning } \\
\hline & & \multirow{2}{*}{$\begin{array}{l}\text { Reasoning } \\
.207 * *\end{array}$} & \multirow{2}{*}{$\begin{array}{l}\text { Reason } \\
\text { ing } \\
\text { principl } \\
\text { es } \\
.241 * *\end{array}$} & \multirow{2}{*}{$\begin{array}{l}\begin{array}{l}\text { Classific } \\
\text { ation }\end{array} \\
.281^{* *}\end{array}$} & \multirow{2}{*}{$\begin{array}{l}\begin{array}{l}\text { Concept- } \\
\text { definitio } \\
\mathrm{n}\end{array} \\
.201^{*}\end{array}$} & \multirow{2}{*}{$\begin{array}{l}\begin{array}{l}\text { Logical } \\
\text { syllogis } \\
\mathrm{ms}\end{array} \\
.255^{* *}\end{array}$} & \multirow{2}{*}{$\begin{array}{l}\text { Indetermin } \\
\text { ate } \\
\text { syllogisms }\end{array}$} & \multirow{2}{*}{$\begin{array}{l}\begin{array}{l}\text { Reading } \\
\text { compreh } \\
\text { ension }\end{array} \\
.501^{* *}\end{array}$} \\
\hline 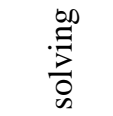 & $\begin{array}{l}\text { Indeterminat } \\
\text { e syllogisms }\end{array}$ & & & & & & & \\
\hline$\frac{\frac{1}{0}}{0}$ & $\begin{array}{l}\text { Flexibility in } \\
\text { calculation }\end{array}$ & $.300 * *$ & $.336 * *$ & $.424 * *$ & $.362 * *$ & $.376^{* *}$ & .042 & $.519 * *$ \\
\hline 苛 & $\begin{array}{l}\text { Understandin } \\
\mathrm{g} \text { of the } \\
\text { number size }\end{array}$ & $.244 * *$ & $.239 * *$ & $.372 * *$ & $.331 * *$ & $.193^{*}$ & -.031 & $.358 * *$ \\
\hline
\end{tabular}

As can be understood from Table 2 all subdimensions concerning the word problem solving performance are positively related to all variables except for the "indeterminate syllogisms" subtest of the syllogistic reasoning test. This suggests that the word problem solving performance is related to both reading comprehension and logical reasoning skills as expected. Having said that, the word problem-solving performance is found not to be related to the "indeterminate syllogisms" although it was predicted to have relations to that. Segers and Verhoeven (2016) conclude that there is a negative relationship between the subdimensions of "logical syllogisms" and "indeterminate syllogisms". A similar result is also found out in the current study suggesting that logical and indeterminate syllogisms are not related $(\mathrm{r}=.356 \mathrm{p}<0.01)$. In other words, the participants have higher scores regarding the logical syllogisms items which require the answers of yes or no, but lower scores in the indeterminate syllogisms items which have the answer of maybe. Research indicates that children do not tend to choose the "maybe" answer even if they understand the premises. When they come across a problem that may have a yes or no answer, they stop analyzing the problem and may not focus on the "maybe" answer (Haars \& Mason, 1986; Segers \& Verhoeven, 2016). In the study conducted by Seger and Verhoeven (2016), the dimensions of syllogisms and indeterminate syllogisms were examined separately in relation to reading comprehension. Their effects, but only the combined effects of both dimensions on reading comprehension could be mentioned. For this reason, in this study, inference skill was evaluated on a single dimension based on the total score obtained from logical syllogisms and indeterminate syllogisms questions.

Baron and Kenny (1986) defined the mediator variable as a variable that could explain the relationship between the predictor and the dependent variable. In the model proposed in this study, it is accepted that reading comprehension skill acts as a mediator between logical reasoning and word problem solving performance. In line with the previous research (Baron \& Kenny, 1986; Hayes, 2009) the following situations should be provided to demonstrate the mediation effect in this model study: (1) logical reasoning skill which is the independent variable should significantly affect both reading comprehension (mediator variable) and word problem-solving performance (dependent variable) and (2) reading comprehension should significantly affect the word problem-solving performance. Also, the causal relationship between logical reasoning performance and word problem-solving performance should significantly be reduced as a result of the integration of the reading comprehension variable (mediating variable) as the predictor of problem-solving performance to the model. 
Table 3 presents the correlation values between the variables included in the study. Thence, both logical reasoning and syllogistic reasoning are positively related to the reading comprehension $(\mathrm{r}=0.48, \mathrm{p}<0.01 ; \mathrm{r}=0.36, \mathrm{p}<0.01)$ and word problem solving performance $(\mathrm{r}$ $=0.57, \mathrm{p}<0.01 ; \mathrm{r}=0.34, \mathrm{p}<0.01)$. These findings support the hypotheses 1 and 2 .

Table 3. Correlations between the variables

\begin{tabular}{lllll}
\hline & 1 & 2 & 3 & 4 \\
\hline 1. Reading comprehension & - & & & \\
\hline 2. Syllogistic reasoning & $.360^{* *}$ & & & \\
\hline 3. Logical reasoning & $.485^{* *}$ & $.410^{* *}$ & & - \\
\hline 4. Word problem solving & $.601^{* *}$ & $.342^{* *}$ & $.570^{* *}$ & \\
\hline
\end{tabular}

$* * \mathrm{p}<.01$

In the model, it is required that independent variables should have a significant correlation with both the mediator variable and dependent variable and that the mediator variable should have a significant correlation with the dependent variable. However, if these values are very high (i.e.,80 or higher), it indicates a problem in the multi-connection issue (Iacobucci, Neela \& Xiaoyan, 2008). The relationships between the independent variables and the mediation variable range between 0.36 and 0.48 . On the other hand, between the dependent variables and the mediation variable range between 0,34 and 0,57. All these relations are statistically significant at .01 . The correlation between reading comprehension and word problem-solving performance is found to be 0,60 . This hints at the fact that a mediation model can be developed among the variables and that there is no multi-connection problem.

To test Hypothesis 3 which asserts that reading comprehension mediates the relationship between logical thinking and word problem-solving Baron and Kenny's (1986) steps regarding the mediation analysis were followed. As can be observed in Table 4 both logical reasoning and syllogistic reasoning skills have positive and statistically significant relations with word problem solving $(\beta=0,570, \mathrm{p}<0.01 ; \beta=0,344, \mathrm{p}<0.01)$. As expected, this finding constitutes a support for the direct effects of logical reasoning skills on word problem solving performance. In the second step of the analysis, the effects of reading comprehension on the logical reasoning skills were examined. The results given in Table 4 demonstrate that both logical reasoning and syllogistic reasoning skills have positive and statistically significant relations with reading comprehension $(\beta=0,532, p<0.01 ; \beta=0,360, p<0.01)$. In the third step of the analysis, the effects of reading comprehension on the word problem-solving performance were examined. The results in Table 4 illustrate that reading comprehension has positive and statistically significant effects on the word problem-solving performance $(\beta=0,607, p<0.01)$. In the final step of the analysis the combined effects of logical reasoning, syllogistic reasoning, and reading comprehension on the word problem-solving performance were analyzed. The results of the analysis (Table 4) exhibit that when reading comprehension is added to the model, the $\beta$ coefficient which indicates the relationships between logical reasoning, syllogistic reasoning and word problem solving is still statistically significant, by the coefficient is found to be lower $(\beta=0.349, \mathrm{p}<0.01 ; \beta=0.049, \mathrm{p}<0.01)$. The mediation effect in any relationship can be either full or partial (Baron \& Kenny, 1986). When the mediator variable is added to the process, if the statistical significance disappears in the direct effect of the independent variable on the dependent variable, it can be argued that there is a mediation effect. However, partial mediation can be mentioned if the direct effect of the independent variable on the dependent variable remains statistically significant (Baron \& Kenny, 1986; Shaver, 2005). The effect of logical reasoning and syllogistic reasoning on word problem 
solving remained significant with the addition of reading comprehension as a means of a variable to the model proposed in the study. However, the decrease in beta values constitutes evidence of the partial mediation role of reading comprehension performance. These findings confirm the mediating role of reading comprehension in the effect of logical reasoning and syllogistic reasoning arguments on word problem solving performance. The results of the mediation analysis, which is realized by providing the model that includes four steps, illustrate evidence for partial mediation (Figure 2).

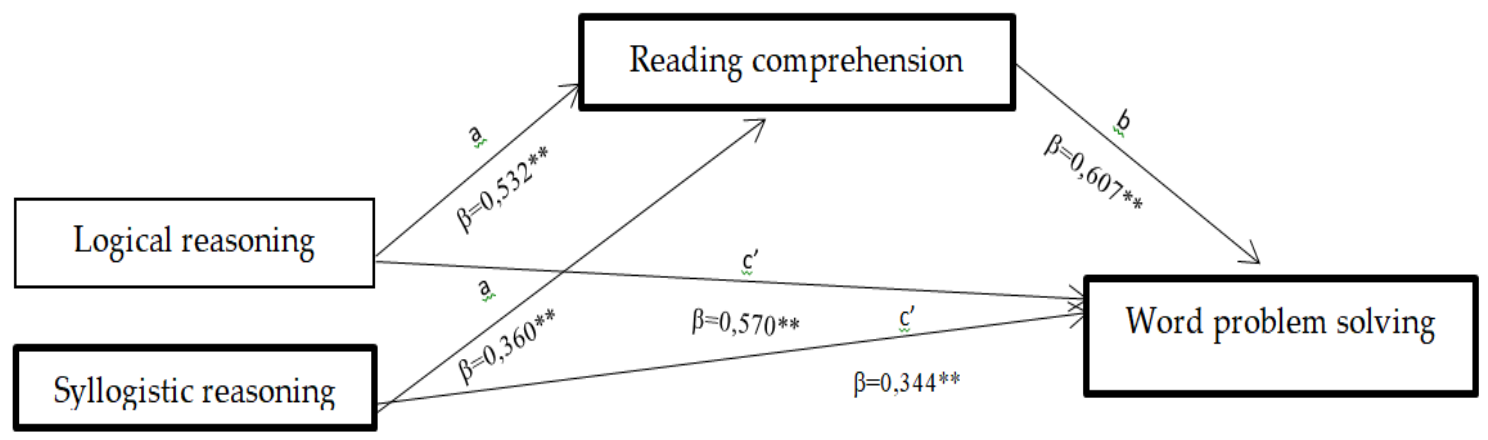

Figure 2. Mediation model for the mediating role of reading comprehension in the relationship between logical thinking and word problem solving

Table 4. Results of regression analysis

\begin{tabular}{lllll}
\hline Independent variables & Dependent variables & $\mathrm{F}$ & $\mathrm{R} 2$ & Beta \\
\hline Logical reasoning & Word problem solving & 75,030 & 0,325 & $0,570^{* *}$ \\
\hline Syllogistic reasoning & Word problem solving & 20,948 & 0,113 & $0,344^{* *}$ \\
\hline Logical reasoning & Reading comprehension & 61,671 & 0,283 & $0,532^{* *}$ \\
\hline Syllogistic reasoning & Reading comprehension & 23,262 & 0,130 & $0,360^{* *}$ \\
\hline Reading comprehension & Word problem solving & 90,956 & 0,368 & $0,607 * *$ \\
\hline $\begin{array}{l}\text { Logical reasoning (LR)+ Syllogistic } \\
\text { reasoning (SR)+Reading } \\
\text { comprehension (RC) }\end{array}$ & Word problem solving & 44,546 & 0,465 & $0,349 * *(\mathrm{LR})$ \\
\hline
\end{tabular}

$* * \mathrm{p}<.01$

Figure 2 illustrates the final version of the model with nonstandard coefficients. Its $\mathrm{R}^{2}$ is 0,46 $(\mathrm{p}<.01)$. The model shows how both logical reasoning and syllogistic reasoning skills directly affect word problem-solving skills together. When the indirect effect of both logical and syllogistic reasoning on word problem solving performance based on reading comprehension is analysed, it is spotted that $95 \%$ reliability interval does not contain zero, $b=0,322$, $\mathrm{SE}=0,033, \mathrm{p}=0.000,95 \%$ CI [0.256-0.389]; $\mathrm{b}=0,312, \mathrm{SE}=0,062, \mathrm{p}=0.000,95 \%$ CI [0.1770.447]. Provided the reliability interval does not contain zero, this provides statistical evidence about the fact that reading comprehension plays a mediation role in the effect of logical and syllogistic reasoning on word problem-solving.

\section{Discussion, Conclusion, and Suggestions}

In this study, the role of reading comprehension skill of students in explaining the relationship between their logical reasoning and their word problem solving performance is focused upon. The results obtained display that there are significant relationships among reading comprehension, word problem solving performance, and logical reasoning skills. It is concluded that students' reading comprehension skill has an indirect and partial effect on the effect of logical reasoning skill, on their word problem solving performance. 
In the analysis of the students' inference skills, two-dimensional questions about logical syllogisms and indeterminate syllogisms were utilized. The items of logical syllogisms require the answers of yes or no. The items of indeterminate syllogisms require the use of the answer of "maybe". One of the findings of the study is that the performances of the students in both dimensions were found to be negatively related to each other. In other words, the students whose performance was good in replying to the questions requiring the yes/no answers could not correctly answer those items entailing the maybe answers. Segers and Verhoeven (2016) claim that the performances of the students in both dimensions were found to be negatively related to each other and that their performance in the latter dimension is much lower. In the study by Can, Altunya and Can (2019) the students were asked to state whether or not the conclusion was certainly based on the following context: "Hasan would bring chocolate if he went to Ankara or Istanbul.", "Hasan brought chocolate." "Then Hasan went to Ankara." The students' performance is found to be lower than their performance in other questions in this question, which contains uncertainty. Previous and present findings clearly indicate that students generally do not tend to consider possible other situations when evaluating the accuracy of the results based on the given premises, and they mostly choose the incorrect option and cannot evaluate other possibilities sufficiently. Also, no significant relationship is found between the students' word problem-solving performance and their inference skills pertaining to indeterminate syllogisms. In the study by Wong (2018) similar findings are declared in that while the students' problem-solving skills were found to be related to inference questions that require a yes / no answer, their skills related to the uncertain inference questions were not seen as a predictor of problem-solving (Wong, 2018).

The relationship between the students' performance in inference questions that call for a yes/no answer, and their logical thinking skills and their word problem-solving performance is found to be positive and statistically significant. In order to analyze the students' logical thinking skills, a test including general logic topics, consisting of reasoning, reasoning principles, classification, and concept-definition dimensions was used. In addition, since word mathematical problems also require good inference skills (Imam, 2016; Malloy \& Jones, 1998), students' inference skills are also concentrated upon in the studies. Although the studies supporting the relationships between these skills are limited (Morsanyi, McCormack \& O’Mahony, 2018; Wong, 2017), their findings are consistent with the relevant research results. The other studies mostly emphasize the relationship between logic and mathematics (Attridge \& Inglis, 2013; Morsanyi et. al., 2013). As a result of this research which provides an understanding of two different cognitive mechanisms that is logical thinking and word problem solving it is seen that in order for one to be a good problem solver their logical thinking should be improved. This result gives evidence about the fact that the learning activities designed to improve students' mathematical problem-solving skills can be associated with logical thinking and inference making skills.

Another point that is scrutinized in the study is the correlations between logical reasoning, inference making, and reading comprehension. Reading comprehension is a complex skill that is based on the functions of other cognitive skills and processes (Cain, Oakhill \& Bryant, 2004). Making inferences, which is one of the high-level skills, helps to structure the text based on meaning (Hannon \& Daneman, 2001). Research suggests that making inferences is closely related to reading comprehension (Cain \& Oakhill, 1999; Cain, Oakhill, Barnes \& Bryant, 2001) which is in concert with the present findings.

Research underpins that there is a correlation between reading comprehension and word problem-solving performance (Bonen, Van Der Schoot, Florytvan, De Vries \& Jolles, 2013; 
Vilenius-Tuohimaa, Aunola \& Nurmi, 2008). In the study by Fuchs et. al. (2015) such results were supported by the longitudinal findings and individual differences were also taken into account. The findings of the study suggest that whilst there is a direct effect of general linguistic comprehension on comprehension of the text, the linguistic structure of the word problem is observed to play a mediating role (Fuchs et. al., 2018). Research pinpoints that word problem-solving skill is a part of reading comprehension, which includes different forms linguistic comprehension, working memory, and reasoning (Kintsch \& Greeno, 1985; Fuchs et. al., 2018). These findings support the direct relationship between word problem-solving performance and reading comprehension and the mediator role of reading comprehension in the logical-mathematical relationship.

In the model tested, it is seen that the observed effect of logical thinking depends on the mediator role of reading comprehension and that reading comprehension creates an indirect effect in the effect of logical thinking skills on word problem-solving performance. This shows that students with improved logical thinking skills are better at word problem solving as a result of their reading comprehension skills. In other words, improving a student's logical thinking skills may increase their math performance. However, if the student's reading comprehension skill is not sufficiently developed, their word problem-solving performance may not be possible to reach the desired level. In the studies, it is found that the skills related to vocabulary knowledge and linguistic comprehension are related to the word problemsolving performances of the students in the following years (Spencer, Fuchs \& Fuchs, 2020). For this reason, it is suggested that literacy development should be supported in connection with logical and syllogistic reasoning, and numeracy skills while preparing training programs to support the development of students with low word problem-solving skills (Spencer, Fuchs \& Fuchs, 2020). This conclusion in the literature provides evidence to support the mediating role of reading comprehension in this research.

Research shows that students who have difficulty in word problem solving, computing, reasoning, and language skills in the first years of school continue to experience similar or even increasing difficulty in word problem-solving performance in the following years (Spencer, Fuchs \& Fuchs, 2020). Interventions that support basic skills like reading comprehension, logical thinking, and syllogistic reasoning can reduce the difficulties students may experience in solving the word problem (Spencer, Fuchs \& Fuchs, 2020). In addition to this, the relationship between word problem-solving performance and logical thinking skills reveals the necessity of reasoning and making inferences when individuals process the word problem-solving mechanism. Accordingly, it is recommended that those practices aimed at increasing students' word problem-solving performances should be carried out in parallel with processes that support verbal and logical reasoning.

There are some limitations of this study such as the sampling method and the number of the participants. Primary school fourth-grade students were included in the study and the participants were identified by convenience sampling. To eliminate this limitation of the research, it is recommended to make further studies with a sample group consisting of more students considering different variables (grade level, socioeconomic level, number of books at home, etc.). This will increase the generalizability of the research results as well as creating an opportunity to test the models for examining the direct and indirect effects of other variables. 


\section{References}

Andersson, U. (2007). The contribution of working memory to children's mathematical word problem solving. Applied Cognitive Psychology, 21(9), 1201-1216. https://doi.org/10.1002/acp.1317.

Attridge, N., \& Inglis, M. (2013). Advanced mathematical study and the development of conditional reasoning skills. PLoS One, 8, e69399.

Bae, Y. S., Chiang, H. M., \& Hickson, L. (2015). Mathematical word problem solving ability of children with autism spectrum disorder and their typically developing peers. Journal of Autism and Developmental Disorders, 45, 2200-2208. https://doi.org/ 10.1007/s10803-015-2387-8.

Baron, R.M. \& Kenny, D.A. (1986). The moderator-mediator variable distinction in social psychological research: Conceptual, strategic, and statistical considerations, Journal of Personality and Social Psychology, 51, 1173-82.

Boonen, A. J. H., Van der Schoot, M., Van Wesel, F., De Vries, M. H., \& Jolles, J. (2013). What underlies successful word problem solving? A path analysis in sixth grade students. Contemp. Educ. Psychol. 38, 271-279. DOI: 10.1016/j.cedpsych.2013.05.001

Burmaoğlu, S., Polat, M., \& Meydan, C. H. (2013). Relational analysis methods in organizational behaviour literature and an investigation on the use of meditational models in Turkish literature. Anadolu University Journal of Social Sciences, 13(1), 1326.

Björn, P. M., Aunola, K. \& Nurmi, J. E. (2016). Primary school text comprehension predicts mathematical word problem-solving skills in secondary school. Educational Psychology, 36(2), 362-377.

Can, D. \& Yetkin Özdemir, İ. E. (2019). An examination of fourth-grade elementary school students' number sense in context-based and non-context-based problems. International Journal of Science and Mathematics Education. https://doi.org/10.1007/s10763-019-10022-3.

Can, D., Altunya, H. \& Can, V. (2019). A research on the logical thinking skills of 8-12 oldstudents. YYU Journal of Education Faculty, 16 (1), 1136-1166.

Cain, K., \& Oakhill, J. V. (1999). Inference making ability and its relation to comprehension failure in young children. Reading and Writing: An Interdisciplinary Journal, 11, 489-503.

Cain, K., Oakhill, J., \& Bryant, P. (2004). Children's reading comprehension ability: Concurrent prediction by working memory, verbal ability, and component skills. Journal of Educational Psychology, 96 (1), 31-42.

Cohen J., Cohen P., West S. G. \& Aiken L. S. (2003). Applied Multiple Regression / Correlation Analysis for the Behavioral Sciences (3rd Edition) Mahwaj, NJ: Erlbaum.

Çetinkaya Özdemir, E. \& Akyol, H. (2019). The development of a reading comprehension test. Universal Journal of Educational Research, 7(2), 563-570.

De Corte, E., \& Verschaffel, L. (1987). The effect of semantic structure on first graders' strategies for solving addition and subtraction word problems. Journal for Research in Mathematics Education, 363-381.

De Smedt, B., Taylor, J., Archibald, L., \& Ansari, D. (2010). How is phonological processing related to individual differences in children's arithmetic skills? Developmental Science, 13, 508-520.

Fraenkel, J.R., Wallen, N.E., \& Hyun, H.H. (2012). How to design and evaluate research in education (Eight Edition). New York: McGraw-Hill.

Fuchs, L.S., Fuchs, D., Compton, D.L., Powell, S.R., Seethaler, P.M., Capizzi A.M. \& Fletcher, J.M. (2006). The cognitive correlates of third-grade skill in arithmetic, 
algorithmic computation, and arithmetic word problems. Journal of Educational Psychology, 98, 29-43. DOI: 10.1037/0022- 0663.98.1.29.

Fuchs, L.S., Fuchs, D., Compton, D.L., Hamlett, C.L., \& Wang, A.Y. (2015). Is wordproblem solving a form of text comprehension? Scientific Studies of Reading, 19, 204223. DOI: $10.1080 / 10888438.1005745$

Fuchs, L.S., Fuchs, D., Stuebing, K., Fletcher, J.M., Hamlett, C.L., \& Lambert, W.E. (2008). Problem-solving and computation skills: Are they shared or distinct aspects of mathematical cognition? Journal of Educational Psychology, 100, 30-47. DOI: 10.1037/0022-0663.100.1.30.

Fuchs, L. S., Gilbert, J. K., Fuchs, D., Seethaler, P. M. \& Martin, B. (2018). Text comprehension and oral language as predictors of word-problem solving: Insights into word-problem solving as a form of text comprehension. Scientific Studies of Reading, $22,1-15$.

Haars, V. J., \& Mason, E. J. (1986). Children's understanding of class inclusion and their ability to reason with implication. International Journal of Behavioral Development, 9(1), 45-63.

Handley, S., Capon, A., Beveridge, M., Dennis, I., \& Evans, J.S.B.T. (2004). Working memory, inhibitory control, and the development of children's reasoning. Thinking \& Reasoning, 10, 175-195.

Hannon, B., \& Daneman, M. (2001). A new tool for measuring and understanding individual differences in the component processes of reading comprehension. Journal of Educational Psychology, 93, 103-128.

Hayes, A. F. (2013). Introduction to mediation, moderation, and conditional process analysis. A regression-based approach. New York: The Guilford Press.

Iacobucci, D. (2008). Mediation Analysis, Thousand Oaks, CA: Sage.

Imam, O., Abas-Mastura, M., \& Jamil, H. (2013). Correlation between reading comprehension skills and students' performance in mathematics. International Journal of Evaluation and Research in Education. 2 (1), 1-8.

Imam, O. (2016). Effects of reading skills on students' performance in science and mathematics in public and private secondary schools. Journal of Education and Learning, 10(2), 177-186.

Inglis, M., \& Simpson, A. (2009). Conditional inference and advanced mathematical study: Further evidence. Educational Studies in Mathematics, 72, 185-198.

Jordan, N. C., Levine, S. C., \& Huttenlocher, J. (1995). Calculation abilities in young children with different patterns of cognitive functioning. Journal of Learning Disabilities, 28(1), 53-64.

Kline, R.B. (2011). Principles and practice of structural equation modeling. 3. New York, NY: Guilford.

Kintsch, W., \& Greeno, J.G. (1985). Understanding and solving word arithmetic problems. Psychological Review, 92, 109-129. DOI: 10.1037/0033-295X.92.1.109

Koğar, H. (2015). Examination of factors affecting PISA 2012 mathematical literacy through mediation model. Education and Science, 179, 45-55.

Koponen, T., Aunola, K., Ahonen, T., \& Nurmi, J.-E. (2007). Cognitive predictors of singledigit and procedural calculation skills and their covariation with reading skill. Journal of Experimental Child Psychology, 97, 220-241.

Malloy, C. E. \& Jones, M. G. (1998). An investigation of American students' mathematical problem solving. Journal for Research in Mathematics Education, 29 (2), 143-163.

Ministry of National Education. (2018). Primary school's mathematics education program for grades 1-4. Ankara, Turkey. 
Morsanyi, K., \& Handley, S.J. (2012). Reasoning on the basis of fantasy content: Two studies with high-functioning autistic adolescents. Journal of Autism and Developmental Disorders, 42, 2297- 2311.

Morsanyi, K., McCormack, T. \& O'Mahony, E. (2018). The link between deductive reasoning and mathematics, Thinking \& Reasoning, 24(2), 234-257, DOI: 10.1080/13546783.2017.1384760

Morsanyi, K., \& Szücs, D. (2015). Intuition in mathematical and probabilistic reasoning. In R. C. Kadosh \& A. Dowker (Eds.), Oxford library of psychology. The Oxford handbook of numerical cognition ( $\mathrm{p}$ 180-200). Oxford University Press. https://doi.org/10.1093/oxfordhb/9780199642342.013.016

Nunes, T., Bryant, P., Evans, D., Bell, D., Gardner, A., Gardner, A. \& Carraher, J. (2007). The contribution of logical reasoning to the learning of mathematics in primary school. British Journal of Developmental Psychology, 25(1), 147-166.

Pape, S.J. (2004). Middle school children's problem-solving behavior: A cognitive analysis from a reading comprehension perspective. Journal for Research in Mathematics Education, 35, 187-219.

Piaget, J. (1952). The child's conception of number. London: Routledge \& Kegan Paul.

Pimperton, H., \& Nation, K. (2010). Understanding words, understanding numbers: An exploration of the mathematical profiles of poor comprehenders. British Journal of Educational Psychology, 80, 255-268.

Russell, B. (1919). Introduction to mathematical philosophy. London: George Allen \& Unwin.

Schröder, E., Bödeker, K., \& Edelstein, W. (2000). The development of syllogistic reasoning: A manual including measurement procedures and descriptive analyses; Study "individual development and social structure"; Data handbooks. Max-Planck-Institut für Bildungsforschung.

Spencer, M., Fuchs, L. S. \& Fuchs, D. (2020). Language-related longitudinal predictors of arithmetic word problem solving: A structural equation modeling approach. Contemporary Educational Psychology, 60, 1-16.

Swanson, H. L., Jerman O., \& Zheng, X. (2008). Growth in working memory and mathematical problem solving in children at risk and not at risk for serious math difficulties. Journal of Educational Psychology, 100, 343-379. DOI:10.1037/00220663.100.2.343.

Tajika, H., Nakatsu, N., Nozaki, H., Neumann, E., \& Maruno, S. (2007). Effects of selfexplanation as a metacognitive strategy for solving mathematical word problems. Japanese Psychological Research, 49(3), 222-233. DOI: http://doi.org/10.1111./j.1468-5884.2007.00349.x.

Thevenot, C., Devidal, M., Barrouillet, P., \& Fayol, M. (2007). Why does placing the question before an arithmetic word problem improve performance? A situation model account. The Quarterly Journal of Experimental Psychology, 60(1), 43-56.

Timmermans, R. E., Van Lieshout, E., \& Verhoeven, L. (2007). Gender-related effects of contemporary math instruction for low performers on problem-solving behavior. Learning and Instruction, 17, 42-54.

Verschaffel, L., Greer, B., \& De Corte, E. (2000). Making sense of word problems. Lisse, The Netherlands: Swets \& Zeitlinger.

Vilenius-Tuohimaa, P. M., Aunola, K., Nurmi, J.E. (2008). The association between mathematical word problems and reading comprehension. Educational Psychology, 28, 409-426. DOI: 10.1080/01443410701708228

Wong, T. T. (2018). Is conditional reasoning related to mathematical problem solving? Developmental Science, 21, 1-12. 
Yuill, N. \& Oakhill, J. (1991). Children's problems in text comprehension. An experimental investigation. Cambridge: Cambridge University Press. 